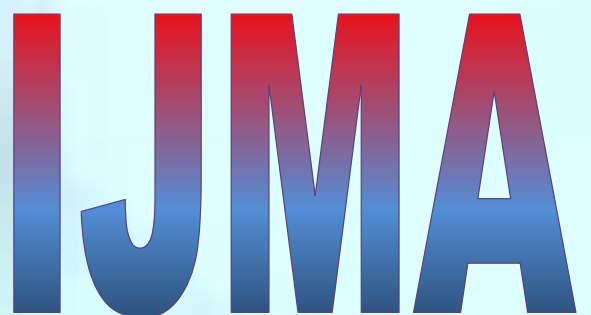

INTERNATIONAL

Journal of MEdical

\section{ARTS}

Volume 3, Issue 1 (Winter 2021)

http://ijma.journals.ekb.eg/

Print ISSN: 2636-4174

Online ISSN: 2682-3780

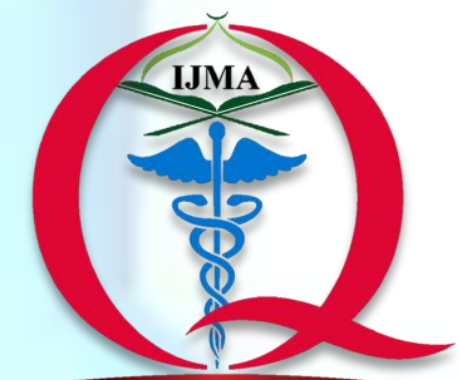

International Jounnal of Medical Arts

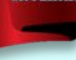





Available online at Journal Website
https://ijma.journals.ekb.eg/

Original article

\title{
On-Pump versus Off-Pump Coronary Artery Bypass Grafting in Patients with Poor Left Ventricular Function
}

\author{
Ahmed Mahmoud Asklany[1]; El-husseiny El-husseiny Gamil[2]; Mohamed Hossiny Mahmoud[2]; Ismail Nasr \\ Elsokkary[2]
}

Department of Cardiothoracic Surgery, Faculty of Medicine, Beni Suef University, Egypt[1]

Department of Cardiothoracic Surgery, Faculty of Medicine, Al-Azhar University, Egypt[2]

Corresponding author: Ahmed Mahmoud Asklany

Email: ahmedasklany0@gmail.com

Received at: August 17, 2020; Revised at: October 21, 2020; Accepted at: October 25, 2020

\section{ABSTRACT}

Background: There is an increase in the number of patients with severely impaired left ventricle function who referred for CABG. Many studies showed that surgical intervention for those high-risk patients has high survival and wonderful outcome compared to medical treatment.

Aim of work: This study aimed to evaluate our experience with coronary artery bypass surgery in patients with EF [ $25 \%$ up to $40 \%$ ] either to perform surgery using off or on-pump technique and try to conclude which technique may be safer regarding cardiac function.

Patients and Methods: This prospective observational patient cohort study from August 2017 to July 2019 enclosed forty consecutive patients divided into 2 teams every 20 patients either off or on pump technique according to surgeons' expertise. Pre-, intra- and post-operative data were collected for all patients. All survivors were subjected to a 6-months follow-up clinically and by Echocardiograghy assessment.

Results: Improvement of ejection fraction [EF] was encountered in our study; the mean 6-months operative EF improved for each team by [36\% versus 37\%] for off-pump and on-pump interventions, respectively. There was no statistically important difference in the information collected for each technique [pvalue $>0.05$ ] regarding most points of comparison.

Conclusion: Results of CABG in high-risk patients were acceptable with on-pump and off-pump techniques with nearly comparable results in our study, at least in the early 6-months after intervention. Intra-aortic balloon usage is valuable when indicated.

Keywords: Coronary revascularization; Off-pump ; On-pump ; Left ventricular dysfunction; Graft.

This article is an open-access article registered under the Creative Commons, ShareAlike 4.0 International license [CC BY-SA 4.0] [https://creativecommons.org/licenses/by-sa/4.0/legalcode.

Please cite this article: Asklany AM, Gamil EE, Mahmoud MH, Elsokkary IN. On-Pump versus Off-Pump Coronary Artery Bypass Grafting in Patients with Poor Left Ventricular Function. IJMA 2021; 3[1]: 1001-1006. DOI: 10.21608/ijma.2020.43316.1175

* Main subject and any subcategories have been classified according to the research topic. 


\section{INTRODUCTION}

During the last thirty years, Coronary-artery bypass graft [CABG] surgery reduced mortality in patients with severe CAD and was performed primarily on the arrested heart by cardiopulmonary bypass machine [1], there are enhancements in symptoms and prolonged survival in patients with on-pump coronary bypass surgery approach, with peri-operative mortality regarding $2 \%$, and extra complications rather than mortality like cardiac infarction, stroke, and kidney disease is regarding $5-7 \%[2]$.

Beating heart surgery developed within the mid-1990s to avoid operative complications like a general inflammatory response, cerebral affection, cardiac depression, and hemodynamic instability [3].

Off-pump as a new surgical revascularization technique is taken into account with negligible harm. Several studies to spot variations between off-pump and on-pump coronary bypass surgery was done [4].

In risky CAD patients, surgical revascularization typically produces poor results \& morbidity. Increasing information demonstrates the benefit of $O P C A B$, therefore, the ensuing decreases in surgical mortality and morbidity, notably among those patients. On the contrary, many previous trials haven't enough variations in stroke, myocardial infarction, renal failure, and death rates when comparing off-pump coronary bypass surgery with on-pump CABG[5].

\section{AIM of THE WORK}

This study aims to evaluate our experience with coronary artery bypass surgery in patients with EF [ $25 \%$ up to $40 \%$ ] to perform surgery using offpump technique or using cardiopulmonary bypass technique and try to conclude which technique may be safer regarding cardiac function and associated morbidities in this high-risk group of patients.

\section{PATIENTS \& METHODS}

From August 2017 and July 2019, forty consecutive patients littered with CAD underwent primary isolated coronary bypass surgery in Kasr El-Aini hospital, Cairo University, and Beni Suef hospital university, Beni-Suef University, who had
EF twenty-fifth up to forty percentage. Twenty patients were operated on with $\mathrm{CPB}$ and twenty patients with OPCAB while not CPB. These patients were organized into two groups; group $A$ enclosed the off-pump cases, and group $B$ enclosed the on pump cases.

Exclusion criteria for both groups: Patients with associated valvular lesions [including ischemic mitral regurgitation], patients with previous open-heart surgery, patients with associated aneurysm of the left ventricle or ischemic VSD defect, ]atients with recent cardiac infarction, patients with liver cell failure, renal failure on regular dialysis, patients with poor respiratory function in COPD patients and Patients with cardiomyopathy [Dyspnea FC 4].

Pre, Intra, and immediate operative information were collected for every patient in each group. All survivors were subjected to 6- months follow-up assessment. The choice of the technique was according to the surgeon's preference and expertise, as some surgeons of each center always performed his intervention with beating heart technique and others on the arrested heart by CPB and had a good expert in his technique. We inserted a femoral artery line for all patients to access the IABP if needed.

On-pump cases: In all the cases, we used standard midline skin incision and median full sternotomy after excluding calcification of aorta cannulation done after full-dose heparin given 300 $\mathrm{IU} / \mathrm{kg}$ and ACT [activated clotting time] $>400 \mathrm{~s}$. Then common atrium cannulation was via 2staged venous cannula $34 \mathrm{~F}$ or $36 \mathrm{~F}$. Cardiac protection was done with ante-grade hot blood cardioplegia without systemic cooling after aorta cross-clamping. We start anastomosis with distal of right coronary or its branches then continuing with the left system with standard separate venous anastomosis, sequential done once target vessels have the nearly equal good caliber and good distal runoff. The last graft anastomosed was the LIMA to $L A D$. Then the proximals were anastomosed to the aorta on beating heart.

OPCAB cases: After giving heparin with half the dose given in on pump cases. We hanged stitches in the pericardium then pulled on a deep pericardial stitch taken inferior and lateral to the 
left inferior pulmonary vein; this cardiac positioning facilitates anastomosing the $\mathrm{OM}$, ramus, and $\mathrm{PL}$ arteries. To elevate the heart, we put large gauze under it then we use Medtronic IV Octopus to stabilize the anastomotic site. Rubber silastic stitches or bulldog clamp was used proximally and distally to control bleeding of the anastomosing coronary vessel. We did not use intracoronary shunts in our procedure. We used a wet air blower [perfered to use carbon dioxide to decrease air embolisim] and hot saline for better visualization. At first, we anastomosed LIMA to LAD, followed by OMs, then DIAGONALS and Ramus Intermedius in the left system. Then we worked distal of the RCA or its branches. We separated saphenous vein anastomosis for the target coronaries and sequential anastomosis in some cases when fulfilling criteria as in on pump cases.

Statistical analysis: Statistical analysis was performed with the SPSS 19.0 applied mathematics computer code package [SPSS, Inc., Chicago, IL]. Quantitative variables were expressed as a mean $\pm S D$ and the qualitative values as percentages. Univariate analysis was achieved by the unpaired $[t]$-test for quantitative and Chi-square to Fisher's Exact test to compare qualitative data. $P$ values $<0.05$ was statistically significant.

\section{RESULTS}

Each group's demographic information failed to show any statistically significant differences from another group [Table 1].

The intra-operative information [Table 2] shows significant statistical differences concerning the length of the procedure in favor of the OPCAB; that was less than on pump as the time needed for cannulation, recirculation, and decannulation. There have been no intra-operative deaths in the study. The conversion from OPCAB to On-Pump in group $B$ occurred once, and this patient had sustained arrhythmias and hemodynamic instability after conducting LIMA to LAD. Thus, we immediately shifted to bypass. Then he received SVG to distal $L A D$, with immediate improvement, and therefore the patient showed a good intra-operative course and weaned from cardio-respiratory bypass with success. In group $B$, two cases had a stormy operative course with failure of the many trials for going off bypass. Those patients died post-operative within the intensive care unit, one within the first postoperative day and the other on the fourth day due to intractable pump failure. The peri-operative Ml was higher in the off-pump than in the on-pump. The incidence of intra-operative arrhythmias was slightly higher within the On-Pump cases, with no statistical difference concerning the atrial or ventricular arrhythmias.

The post-operative information [Table 3] showed statistical difference variations in favor of the OPCAB, except postoperative complications like kidney disease and CNS complications. There has been one hospital mortality in the off-pump immediate postoperative in ICU due to persistent ventricular fibrillation not responding to electrical cardioversion. However, in the on-pump group, there were two mortalities. Bleeding required re-opening for exploration within the on-pump group reported in three patients [15\%] compared to one patient [5\%] within the off-pump group. There was no statistically significant regarding cardiac infarction events, which was higher in on pump [15\%] compared to [10\%] within the off-pump group. Similarly, there had been no statistically significant difference between the two groups regarding kidney disease or postoperative intra-aortic balloon employment. Follow up Echo elucidated no significant distinction between the two teams regarding the modification in LV ejection fraction [LVEF].

Table [1] Preoperative demographic data of studied populations

\begin{tabular}{|l|c|c|c|}
\hline & Group A [n:20] & Group B [n:20] & P-value \\
\hline Mean age [years] & $57.8 \pm 4.2 \%$ & $56.7 \pm 6.1 \%$ & 0.68 \\
\hline Hypertension & $12[60 \%]$ & $12[60 \%]$ & 0.7 \\
\hline Diabetes mellitus & $15[75 \%]$ & $13[65 \%]$ & 0.66 \\
\hline Left main & $7[35 \%]$ & $5[25 \%]$ & 0.65 \\
\hline Peripheral vascular disease & $3[15 \%]$ & $2[10 \%]$ & 0.58 \\
\hline EF\% & $34.1 \% \pm 3.2$ & $35.2 \% \pm 3.4$ & 0.6 \\
\hline
\end{tabular}


Table [2] Intra-operative data of studied populations

\begin{tabular}{|l|c|c|c|}
\hline & Group A [n:20] & Group B [n:20] & P-value. \\
\hline Length of operation [hours] & $2.6 \pm 1.6$ & $3.9 \pm 2.1$ & 0.04 \\
\hline Average number of grafts & $3 \pm 0.6$ & $3.2 \pm 1.1$ & 0.67 \\
\hline Sequential grafts & $4[20 \%]$ & $6[30 \%]$ & 0.33 \\
\hline Intra-operative inotropic support & $14[70 \%]$ & $18[90 \%]$ & 0.039 \\
\hline AF & $2[10 \%]$ & $3[15 \%]$ & 0.2 \\
\hline Ventricular arrhythmia & $3[15 \%]$ & $4[20 \%]$ & 0.3 \\
\hline Intra-operative mortality & 0 & 0 & 0.7 \\
\hline Difficult weaning off bypass & - & $1[5 \%]$ & - \\
\hline Conversion to on-pump & $1[5 \%]$ & - & - \\
\hline
\end{tabular}

Table [3] Post-Operative data of studied populations

\begin{tabular}{|l|c|c|c|}
\hline \multicolumn{1}{|c|}{ Variable } & Group A & Group B & P-Value \\
\hline Hospital mortality & $1[5 \%]$ & $2[10 \%]$ & 0.56 \\
\hline Myocardial infarction & $2[10 \%]$ & $3[15 \%]$ & 0.57 \\
\hline Bleeding and exploration & $1[5 \%]$ & $3[15 \%]$ & 0.03 \\
\hline Atrial fibrillation & $3[15 \%]$ & $5[25 \%]$ & 0.04 \\
\hline Renal Failure & 0 & 0 & - \\
\hline Neurologic complications & 0 & 0 & - \\
\hline IABP use & $3[15.0 \%]$ & $2[10.0 \%]$ & 0.66 \\
\hline ICU Stay [Hours] & $29.90 \pm 9.78$ & $47.87 \pm 8.96$ & 0.001 \\
\hline Hospital Stay [Days] & $9.80 \pm 5.64$ & $12.86 \pm 9.86$ & 0.031 \\
\hline Inotropic drugs use & $12[60 \%]$ & $16[80 \%]$ & 0.032 \\
EF\% first week & $31.2 \% \pm 3.5$ & $32.1 \% \pm 3.2$ & 0.6 \\
EF\% third month & $36.8 \% \pm 7$ & $37.1 \% \pm 8.7$ & 0.65 \\
EF\% six month & $37.2 \% \pm 4$ & $37.5 \% \pm 5$ & 0.62 \\
\hline
\end{tabular}

\section{DISCUSSION}

Although open-heart surgery in low EF patients is risky, the end-result is far favorable than medically treated patients ${ }^{[6]}$. The CPB employment carries several risks on $\mathrm{EF}$, and therefore these risks are multiplied in low EF. There have been unfavorable outcomes and complications with CPB use in several studies in patients with low EF $<35 \%[7]$. There have been important evidence in recent literature comparing risky $C A D$ patients undergoing $\mathrm{OPCAB}$ versus on-pump open-heart surgery. Many retrospective studies favor OPCAB in risky patients as they disclosed an overall mortality benefit over C-CABG[8]. In theory, Organ hazardous effects by CPB and generalized inflammation and blood element damage are well avoided by adopting the OPCAB technique. Several surgeons believe that risky CAD patients can perform OPCAB over the on-pump technique [9]. In our study, we select cases without randomization, having exclusion criteria to unify the risk factors, minimizing them to the low ejection fraction. The demographic data were peculiar in some aspects like the low age, as this can be the incidence within the Middle East region in addition to the gender. During this analysis, we reported patients with additive EuroSCORE of $>5$, subjected to OPCAB and compared them with those that had standard on-pump surgery with the same risk score. The operative findings were much more or less concomitant with many studies about this subject except the length of the operation that was due to the long expertise in OPCAB, the number of grafts conjointly was nearly similar as we have not to under-revascularize even in enlarged hearts, as in those patients we open pleura of the right side and the pleurodiaphragmatic reflection permitting the heart to come entirely within the right cavity to perform simply anastomoses of the OMs or the Ramus Intermedius artery. There were no technical variations as regards the sequential or separate vein grafts. The inotropic support was higher in group $B$ than group $A$, ensuring global ischemia instead of regional ischemia within the OPCAB. 
The postoperative AF was higher in on pump cases. The ejection fraction within the OPCAB had a better result within the first $6^{\text {th }}$ months postoperatively. We also recorded the reduction in operative time, bleeding and re-exploration, duration of mechanical ventilation, intensive care unit stay, and hospital stay in high-risk OPCAB patients. On the opposite hand, we found no applied difference between each team within the current study within the prevalence of postoperative cardiac infarction or intra-aortic balloon pump employment postoperatively.

Neurological insult is a common complication with open-heart surgery, stroke incidence starting from three to nine percent, this may raise mortality from four to nineteen percent [9]. Mechanisms for post-cardiac surgery stroke may be cerebral hypoperfusion or thromboembolic events[10]. Thus, CPB plays a significant role in these mechanisms. Wu et al. mentioned that CPB's use multiplies the danger of stroke by 4.6 times in patients with a EuroSCORE five[11]. Moreover, Patel et al. showed that $O P C A B$ significantly had lower stroke rates than $\mathrm{C}-\mathrm{CABG}$; therefore, in $\mathrm{OPCAB}$, there are no circulating emboli produced by the bypass circuit throughout the procedure[12]. In our study, we have no neurological complications in both groups. It is like Velioglu and Yuksel's, as they mentioned that the stroke incidence is the same in OPCAB and C-CABG[13]. Similarly, other studies $[9,10,14]$ reported a significant decrease in neurologic complications and stroke once avoiding $\mathrm{CPB}$ in risky CAD patients.

There has been a conflict on whether or not OPCAB beneficial concerning mortality. In contrast, abundant reports recorded significantly a lower mortality in off-pump patients[15]; others recognized no significant distinction between the 2 interventions ${ }^{[9,16]}$. We did not reach a significant difference between both hospital mortality techniques and in sex months postoperative. These results agreed with two RCTs conducted on patients over seventy-five years[15,17]. Similarly, Cavallaro et al. studied 80,000 revascularizations in high-risk patients [eighty-five years, COPD, renal disorder, peripheral artery disease, and aortic atherosclerosis] with and without bypass.
They discovered no distinction in early mortality between the two maneuvers ${ }^{[18]}$. In a Meta-analysis by Moller et al. [19] and our study found that early postoperative AF incidence was less in the OPCAB team. Velioglu and Yuksel reported the same. Moreover, they found that the AF tends to recur a lot in C-CABG patients ${ }^{[13]}$. In controversy, Puskas et al. [20], Tariq et al.[21], and Al-Ruzzeh et al.[22] reported that operative AF incidence didn't show an advantage in OPCAB over C-CABG.

Study limitations: The limited number of patients was one of the important limitations in our study, resulting in an inability to get any statistically important distinction in each technique. Lack of randomization within the study subjected it to choice bias limiting the study to a brief amount of follow-up of 6- months only, leading to failure to achieve important conclusion of advantages of off-pump over on-pump technique. Several essential follow-up information weren't accurately assessed because of socioeconomic obstacles as CT coronary angiography to follow up graft patency within the follow-up period.

Conclusion: Although we couldn't show the advantage of OPCAB over C-CABG regarding mortality, it otherwise failed to incur the magnified risk of mortality. On the opposite hand, OPCAB showed good results concerning postoperative AF, kidney failure, conjointly with the reduction within the time of mechanical ventilation, ICU, and hospital stay was reported. These reductions in morbidity improve utilization of resources, which may have a significant impact the financial prices. Off-pump CABG seems to be valuable in this high-risk group of patients with additional co-morbidities. However, larger studies are needed to confirm this point.

Financial and Non-Financial Relationships and Activities of Interest: None

\section{REFERENCES}

1. Hoffman SN, TenBrook JA, Wolf MP, Pauker SG, Salem DN, Wong JB. A meta-analysis of randomized controlled trials comparing coronary artery bypass graft with percutaneous transluminal coronary angioplasty: one-to eight-year outcomes. J Am Coll Cardiol. 2004; 41[8]:1293-1304. DOI:10.1016/S0735-1097[03]00157

2. Lamy A, Devereaux PJ, Prabhakaran D, Taggart DP, Hu S, Paolasso E, et al. Off-pump or on-pump coronaryartery bypass grafting at 30 days. $\mathrm{N}$ Engl J Med 2012;366:1489e97. DOI: 10.1056/NEJMoa1200388 
3. Chang WI, Kim KB, Kim JH, Ham BM, Kim YL. Hemodynamic changes during posterior vessel off-pump coronary artery bypass: comparison between deep pericardial sutures and vacuum-assisted apical suction device. Ann Thoracic Surg. 2004;78[6]:2057-2062 DOI: 10.1016/j.athoracsur.2004.05.059

4. Gerola LR, Buffolo E, Jasbik W, Botelho B, Bosco J, Brasil LA, Branco JN. Off-pump versus on-pump myocardial revascularization in low-risk patients with one or two vessel disease: a multicenter randomized controlled trial. Ann Thorac Surg. 2004;77(2):569-73. DOI:10.1016/S0003-4975(03)01353-5.

5. Gaudino M, Glieca F, Alessandrini F, Nasso G, Pragliola $\mathbf{C}$, Luciani $\mathbf{N}$, et al. High risk coronary artery bypass patient: incidence, surgical strategies, and results. Ann Thorac Surg 2004;77:574e80. DOI: 10.1016/ S0003-4975[03]01534-0

6. Khaled S, Kasem E, Fadel A, Alzahrani Y, Banjar K, Al-Zahrani W, Alsulami H, Allhyani MA Left ventricular function outcome after coronary artery bypass grafting, King Abdullah Medical City [KAMC]. Egypt Heart J. 2019 Aug 5;71[1]:2. DOI: 10.1186/s43044-019-0002-6.

7. Darwazah AK, Bader V, Isleem I, Helwa K. Myocardial revascularization using on-pump beating heart among patients with left ventricular dysfunction. J Cardiothorac Surg 2010;5:109. DOI: 10.1186/1749-8090-5-109

8. Puskas JD, Thourami VH, Kilgo P, Cooper W, Vassiliades T, Vega JD, et al. Off-pump coronary artery bypass disproportionately benefits high-risk patients. Ann Thorac Surg 2009;88:1142e7. DOI: 10.1016/j.athoracsur. 2009.04.135

9. Arslan U, Calik E, Tekin Al, Erkut B. Off-pump versus on-pump complete coronary artery bypass grafting: Comparison of the effects on the renal damage in patients with renal dysfunction.Med [Baltimore]. 2018; 97 [35]:e12146. DOI: 10.1097/MD.0000000000012146

10. Baufreton C. Role of surgical factors in strokes after cardiac surgery. Arch Cardiovasc Dis 2010; 103[5]: 326e32 DOI: 10.1016/j.acvd.2009.12.007

11. Wu CY, Wang SH, Shang YQ, Xia JH. J Huazhong Incidence of atrial fibrillation after off-pump versus onpump coronary artery bypass grafting: A meta-analysis of randomized clinical trials and propensity score matching trials. Univ Sci Technolog Med Sci. 2017 Dec;37[6]:956964. DOI: 10.1007/s11596-017-1834-5.

12. Patel NC, Grayson AD, Jackson M, Au J, Yonan N, Hasan $\mathbf{R}$, et al. The effect off-pump coronary artery bypass surgery on in-hospital mortality and morbidity. Eur J Cardiothorac Surg 2002;22:255e60 DOI: 10.1016/ s1010-7940[02]00301-9

13. Velioglu Y, Yuksel A. Predictors of Postoperative Atrial Fibrillation after Beating-Heart Coronary Artery Bypass Surgery: Is Cardiopulmonary Bypass a Risk Factor? Acta
Cardiol Sin. 2019 Sep;35[5]:468-475. DOI: 10.6515/ ACS.201909_35[5].20190325A.

14. Bargagna M, Belluschi I, Alfieri O. Controversies in cardiac surgery: do multivessel arterial revascularization and beating heart bypass operations improve prognosis? Eur Heart J Suppl. 2019 Mar;21[Suppl B]: B3-B4. DOI: 10.1093/eurheartj/suz004.

15. Cottrell JE, Hartung J. Anesthesia and Cognitive Outcome in Elderly Patients: A Narrative Viewpoint. J Neurosurg Anesthesiol. 2020 Jan;32[1]:9-17. DOI: 10. 1097/ANA.0000000000000640

16. Guan Z, Guan X, Gu K, Lin X, Lin J, Zhou W, et al. Short-term outcomes of on- vs off-pump coronary artery bypass grafting in patients with left ventricular dysfunction: a systematic review and meta-analysis $\mathrm{J}$ Cardiothorac Surg. 2020;15[1]:84. DOI: 10.1186/s13019020-01115-0.

17. Houlind K, Kjeldsen BJ, Madsen SN, Rasmussen BS, Holme SJ, Nielsen PH, et al. On-pump versus off-pump coronary artery bypass surgery in elderly patients: results from the Danish on-pump versus off-pump randomization study. Circulation 2012;125[20]:2431e9. DOI: 10.1161/ CIRCULATIONAHA.111.052571

18. Cavallaro P, Itagaki S, Seigerman M, Chikwe J. Operative mortality and stroke after on-pump vs. offpump surgery in high-risk patients: an analysis of 83914 coronary bypass operations. Eur J Cardiothorac Surg 1 January 2014;45[1]:159e64. DOI: 10.1093/ejcts/ezt221

19. Moller CH, Penninga L,Wetterslev J, Steinbrüchel DA, Gluud C. Off-pump versus on-pump coronary artery bypass grafting for ischaemic heart disease. Cochrane Database Syst Rev 2012;3. CD007224. DOI: 10.1002/ 14651858.CD007224.pub2

20. Puskas JD, WilliamsWH, Duke PG, Staples JR, Glas $\mathrm{KE}$, Marshall JJ, et al. Off-pump coronary artery bypass grafting provides complete revascularization with reduced myocardial injury, transfusion requirements, and length of stay: a prospective randomized comparison of two hundred unselected patients undergoing off-pump versus conventional coronary artery bypass grafting. J Thorac Cardiovasc Surg 2003;125:797e808. DOI : 10.1067/mtc.2003.324.

21. Tariq K, Zia K, Mangi A, Amanullah M, Chaudry PA, Karim M. Conversion from Off to On-Pump Coronary Artery Bypass Grafting. Is it Avoidable? Cureus. 2020 Jan 27;12[1]:e6791. DOI: 10.7759/cureus.6791.

22. Al-Ruzzeh S, George S, Bustami M, Wray J, Ilsley C, Athanasiou $\mathrm{T}$, et al. Effect of off-pump coronary artery bypass surgery on clinical, angiographic, neurocognitive, and quality of life outcomes. BMJ 2006; 332: 1365. DOI: 10.1136/bmj.38852. 479907.7c. 


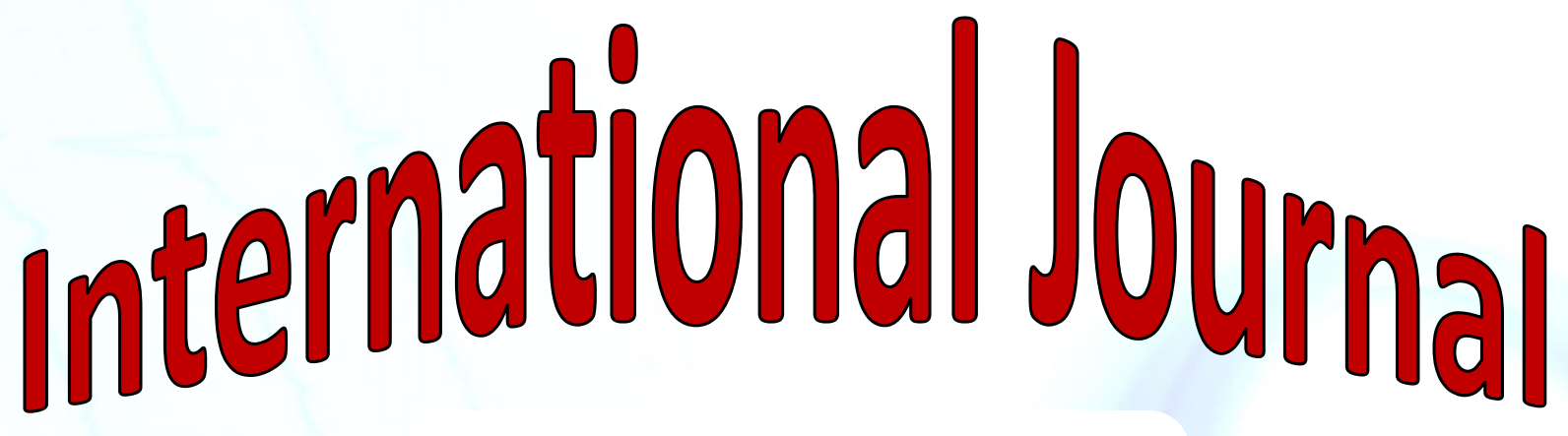

https://ijma.journals.ekb.eg/

Print ISSN: 2636-4174

Online ISSN: 2682-3780

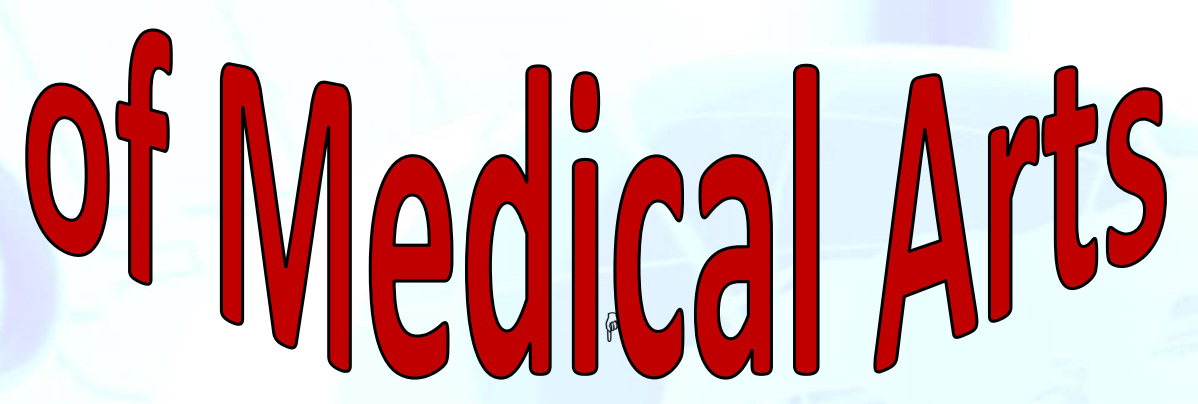

